\title{
ACOMETIMENTO PULMONAR EM CRIANÇAS COM A SíndROME DA IMUNODEFICIÊNCIA HUMANA (AIDS): ESTUDO CLÍNICO E DE NECRÓPSIA DE 14 CASOS
}

I.T.R. Yparraguirre*, C.C. Sant'Anna, V.G.S. Lopes, K. Madi

Hospital UniversitárioAntônio Pedro, Niteróie Instituto dePuericulturae Pediatria MartagãoGesteira, Rio de Janeiro, RJ

RESUMO - OBjetivos. Descrever os aspectos clínicos, laboratoriais, radiológicos e anatomopatológicos encontrados em tecidos pulmonares de necrópsias de crianças com Aids e acometimento pulmonar.

Métodos. Foram revisados, retrospectivamente, prontuários, radiografias simples de tórax e laudos de necrópsias de 14 crianças com Aids e acometimento pulmonar.

Resultados. Oito casos eram do sexo masculino e seis do feminino. As idades variaram de três meses a nove anos, mediana de $\mathbf{I}, 2$, sendo nove deles menores de dois anos. $A$ transmissão foi vertical em 10 pacientes, dos quais cinco mães tinham história de contaminação por relação heterossexual; três, por hemotransfusão e em duas, ignorada. Pneumonia $(n=8)$, candidíase oral $(n=8)$ e diarréia $(n=5)$ foram as doenças prévias mais referidas. $O$ s sinais e sintomas observados à internação foram febre $(n=12)$, dispnéia $(n=10)$, tosse $(n=I I)$, linfoadenomegalia $(n=I I)$, hepato e/ou esplenomegalia $(n=10)$, desnutrição $(n=9)$, palidez $(n=8)$, cianose $(n=5)$ e baqueteamento digital $(n=2)$. Os achados radiológicos mais comuns foram infiltrados difusos $(n=6)$ e condensaçōes $(n=5)$. As alteraçōes histológicas pulmonares foram compatíveis com pneumonia pelo citomegalovírus $(n=9)$, por bactérias $(n=8)$, por Pneumocystis carinii $(n=3)$, por Hystoplasma capsulatum $(n=I)$, por Toxoplasma gondii $(n=I)$ e pneumonia intersticial linfocítica $(n=I)$. A associação CMV e bactéria foi observada em seis casos.

Conclusōess. Houve predomínio de menores de dois anos, de transmissão vertical, de quadro clínico inespecífico de doença pulmonar e de infiltrados e condensações à radiografia. Citomegalovírus e bactérias foram os agentes mais comuns, sendo freqüente a sua associação. Pneumonia Intersticial Linfocítica e Pneumonia pelo $P$. carinii não foram causas freqüentes de doenças pulmonares.

Unttermos: Pneumonia. Crianças. Aids. Necropsias.

\section{INTRODUÇÃO}

Praticamente, todos os órgãos e sistemas podem ser comprometidos na infecção pelo vírus da imunodeficiência humana. $O$ envolvimento pulmonar é a manifestação mais freqüente da síndrome, sendo responsável por dois terços dos sintomas apresentados por crianças menores de um ano de idade (Hauger, 1991). As pneumonias bacterianas, geralmente, são recorrentes e constituem a principal causa de internação. As bactérias isoladas costumam ser as en-

\footnotetext{
*Correspondência:

RuaSanta Rosa, 134/702

Cep: $24220-120-N i t e r o ́ i-R J$
}

contradas em crianças da mesma faixa etária e sem imunodeficiência. Os indivíduos infectados pelo HIV também estão mais predispostos a pneumonias causadas por outros germes, geralmente oportunistas, tais como protozoários, vírus, fungos e micobactérias (Bye, Cairns-Bazarin, Ewig, 1994).

Nos países em desenvolvimento, a dificuldade de acesso a métodos diagnósticos invasivos para investigação de acometimento pulmonar em pacientes com Aids, principalmente em crianças, faz com que, na maioria das vezes, a etiologia da doença pulmonar seja baseada no quadro clínicoradiológico (Lambert, Nogueira, Abreu,
1996). Nessas circunstâncias, a realização de necrópsia torna-se fundamental para o reconhecimento dos agentes causais mais prevalentes. Entretanto, a sua realização é limitada, principalmente na infância, sendo poucos os estudos clínico-patológicos desenvolvidos em crianças (Moran et al. 1994).

Em revisão bibliográfica, em fontes como MEDLINE e LILACS, não registramos trabalho brasileiro publicado sobre o estudo clínico-patológico de crianças com Aids e acometimento pulmonar. Este trabalho se justifica como um esforço preliminar para obtenção de dados de uma população de crianças internadas em hospitais universitários a fim de se reconhecer o perfil clínico- 
patológico da Aids entre as crianças infectadas pelo HIV e com doença pulmonar de nosso meio, contribuindo para o melhor conhecimento do acometimento pulmonar da Aids em crianças que evoluíram para o óbito.

\section{Métodos}

Estudo retrospectivo, descritivo de 14 crianças com Aids e acometimento pulmonar, internadas em hospitais universitários como o HUAP - UFF e o IPPMG - UFRI que evoluíram para o óbito e foram submetidas à necrópsia entre janeiro de 1989 e dezembro de 1996.

Foi utilizado o processo de amostragem não probabilística, tendo sido encontrados 31 casos de crianças com Aids que foram submetidas à necrópsia, 16 do HUAP e 15 do IPPMG. Desse total, foram incluídos no estudo I4 casos (45,1\%) com acometimento pulmonar, sendo I I do HUAP e três do IPPMG

Foi preenchido formulário através da revisão de prontuários e de laudos de necrópsias. A análise dos resultados foi feita através de estatística descritiva. Para as variáveis discretas foram calculadas as distribuições de freqüência e para as variáveis contínuas, as medidas de tendência central e dispersão, segundo à metodologia estatística clássica .

\section{Resultados}

Os dados demográficos e a forma de transmissão do HIV nas 14 crianças estudadas encontram-se nas Tabelas I e 2, respectivamente.

Quanto à história patológica pregressa de cada criança estudada, descrita no prontuário, ocorreu pneumonia recorrente em oito; candidíase oral em oito; diarréía em cinco casos; tuberculose pulmonar em uma; febre em uma e sepse em uma. Houve concomitância de mais de uma doença no

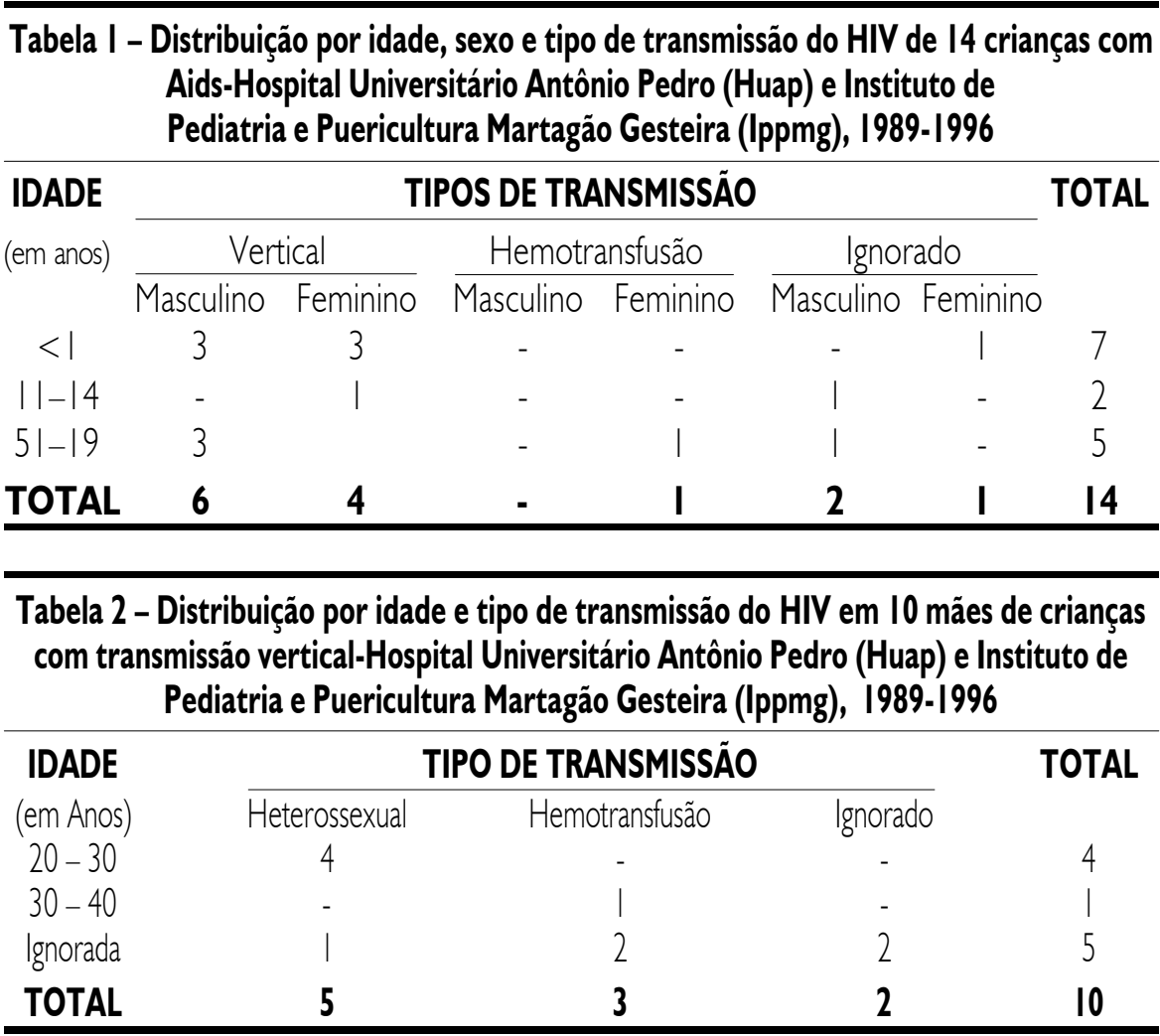

mesmo paciente em vários casos.

$O$ estudo de sinais e sintomas mostrou que 12 crianças referiam febre; 11 , tosse e 10, desconforto respiratório à época da internação que levou ao óbito. Havia mais de uma queixa numa mesma criança. Para análise do intervalo de confiança do tempo de evolução dessas variáveis foram considerados somente os casos em que esse tempo era conhecido. Desta forma, para febre utilizou-se nove casos, para tosse, oito e para dispnéia, sete. O nível de significância considerado foi 0,05, com nível de confiança de $95 \%$. Neste sentido, o tempo médio de evolução, em dias, da febre variou de $38,3 \pm 17,4$; de tosse, de $36 \pm 18,5$ e de dispnéia, de 15,6 \pm 7,9.

Ao exame físico à internação, I | crianças apresentavam linfoadenomegalia generalizada; 10, hepatoesplenomegalia; nove, desnutrição protéicoenergética; oito, palidez cutâneo-mucosa; cinco, cianose; duas, baqueteamento digital, ressaltando-se a ocorrência de mais de um sinal numa mesma criança.

O exame anatomopatológico foi realizado em todos os casos (Tabela 3). A pneumonia pelo CMV foi diagnosticada, à histologia, em nove casos. Os pulmões desses pacientes apresentavam aspecto macroscópico em mosaico, consistência uniformemente aumentada e crepitação diminuída, associado a espessamento septal, com presença de linfócitos e plasmócitos; hiperplasia do epitélio de revestimento alveolar, contendo célula aumentada de volume com inclusão basofilica intranuclear, circundada por halo claro e, por vezes, com granulações grosseiras, também basofilicas, na membrana nuclear, conferindo aspecto de "olho de coruja", conhecida como célula citomegálica. Foram observadas também membranas hialinas, revestindo luzes alveolares, afluxo mononuclear em paredes brônquicas e bronquiolares, hiperplasia do epitélio de revestimento de tais estruturas, contendo, em áreas, células com as características da célula citomegálica. 
O achado de afluxo inflamatório constituído por polimorfonucleares neutrófilos, ocluindo parcialmente luzes alveolares, brônquicas e bronquiolares; necrose de parede vascular e, por vezes, do tecido pulmonar, acrescido da presença de bactérias gram positivas ou negativas, permitiu o diagnóstico de broncopneumonia em oito pacientes.

O diagnóstico de pneumonia pelo $P$. carinii foi estabelecido em três casos pelo exame microscópico de tecido pulmonar que evidenciou material eosinofilico, de aspecto espumoso, contendo pontilhado negro à coloração pela H/E e pelo Grocott, com evidencia de microorganismos com características morfológicas de $P$. carinii.

Em um caso, o estudo histológico mostrou espessamento septal e afluxo de mononucleares, associado à inúmeros linfócitos aglomerados, compondo nódulos no parênquima pulmonar, permitindo a formulação do diagnóstico de Pneumonia Intersticial Linfocítica.

Em um caso havia espessamento septal com celularidade aumentada por afluxo linfo-plasmocitário e presença de diminutas formas arredondadas, em meio à fibrina, nas luzes alveolares, com características de H. capsulatum, confirmadas pela coloração pela prata.

Em um caso foi observado espessamento septal com afluxo linfo-plasmocitário, algumas células de revestimento alveolar aumentadas de volume, com membrana celular espessada e com inúmeros microorganismos no seu interior. A coloração pela prata metanamina mostrou características morfológicas do pseudocisto do $T$. gondii.

Em nove casos foram encontrados mais de um patógeno ao exame histopatológico dos tecidos pulmonares analisados, sendo que em seis estavam associados CMV e bactéria e em três, CMV e Pneumonia pelo P. carinii.

Os dados clínicos, radiográficos, gaso- métricos e histopatológicos de todos os pacientes analisados estão listados na Tabela 4.

\section{Discussão}

Uma vez que a Aids foi reconhecida relativamente há pouco tempo, os estudos histopatológicos têm contribuído para o melhor conhecimento da sua fisiopatologia e, conseqüentemente, para implementação de medidas profiláticas e terapêuticas, visando melhorar a sobrevida dos pacientes. Johann-Liang, Cervia \& Noel (1997), em Nova lorque, realizaram estudo retrospectivo de 58 óbitos de crianças infectadas pelo HIV entre 1990 e 1996. As crianças infectadas pelo HIV, falecidas em 1996, eram mais velhas, linfopênicas, tinham maior tendência a envolvimento de mais de um órgão e a ter recebido terapia antiretroviral e antimicrobiana do que as de 1990. No grupo de 1996, nenhuma criança faleceu por pneumonia pelo $P$. carinii e as infecções oportunísticas que mais comumente estiveram associadas ao óbito foram M. avium-intracellulare e Pseudomonas aeruginosa. Tais resultados demonstram os avanços na terapia antiretroviral e a eficácia da profilaxia para as infecções oportunísticas, especialmente a pneumonia pelo $P$. carinii. No presente estudo, por ser constituído de população originária de períodos e de duas instituições universitárias diferentes, não foi possível tal análise.

De acordo com dados de revisão de casos de Aids em crianças notificados ao CDC, até 1996, a idade do diagnóstico de infecção pelo HIV do grupo com transmissão vertical foi por volta dos 18 meses de idade, com aproximadamente $80 \%$ do total dos casos diagnosticados antes dos cinco anos (Centers for Disease Control and
Prevention, 1996). No Rio de Janeiro, até abril de 1998, 63\% dos casos notificados de Aids pediátrica, independentemente do tipo de transmissão, ocorreram nessa mesma faixa etária (Boletim DST/Aids, 1998). Nossa amostra constituiu-se de crianças com faixa etária mais baixa, sendo nove $(64,4 \%)$ delas, menores de dois anos de idade.

As crianças infectadas pelo HIV por via vertical apresentam curso clínico bimodal, com a maior parte delas evoluindo de forma lenta. Apenas 15\% evoluem rapidamente, falecendo durante os dois primeiros anos de vida (Courpotin, 1997). No presente estudo, cuja maioria dos casos tinha transmissão vertical, a faixa etária mais acometida foi a de menores de dois anos de idade. Nossos resultados coincidem com outros estudos de necrópsias e biópsias em crianças com infecção pelo HIV/Aids (Reik, Rodriguez \& Hensley, 1995; Joshi et al., 1986), refletindo, provavelmente, o grupo de curso clínico mais rápido, cujo início dos sintomas é precoce e de pior prognóstico.

Nossos resultados não mostraram diferença de gênero entre os pacientes, à semelhança da literatura (Parks, 1996; Boletim DST/Aids, 1998), embora os estudos anatomoclínicos de Moran et al. (1994), Reik, Rodriguez \& Hensley (1995), Joshi et al. (1986), tenham encontrado predomínio do sexo masculino.

Estudos anatomodínicos em pacientes HIV positivos têm mostrado que o quadro clínico pulmonar costuma ser inespecífico, 
Tabela 4 - Achados clínico-patológicos de 14 crianças com Aids-Hospital Universitário Antônio Pedro (Huap) e Instituto de Pediatria e Puericultura Martagão Gesteira (Ippmg), 1989-1996

\begin{tabular}{|c|c|c|c|c|c|c|c|c|}
\hline Caso & $\begin{array}{l}\text { Número de } \\
\text { Necrópsia }\end{array}$ & Idade & Transmissão & $\begin{array}{l}\text { Sinais } \\
\text { Clínicos }\end{array}$ & Gasometria & $\begin{array}{c}\mathbf{R X} \\
\text { (padrão) }\end{array}$ & Tratamento & Histopatologia \\
\hline I* & A89/89 & 9 anos & Ignorada & $\begin{array}{l}\text { tosse,febre, } \\
\text { DPC }\end{array}$ & normal & condensação & $\begin{array}{l}\text { ABT, SMZ/ } \\
\text { TMP, ANF B }\end{array}$ & $\begin{array}{l}\text { PNM bacteriana e } \\
\text { PMN CMV }\end{array}$ \\
\hline $2 *$ & A $84 / 91$ & 7 anos & $\begin{array}{l}\text { Hemo } \\
\text { transfusão }\end{array}$ & $\begin{array}{l}\text { tosse, dispnéia, } \\
\text { febre, DPC }\end{array}$ & hipóxia & infiltrado & SMZ/TMP & $\begin{array}{l}\text { PNM bacteriana e } \\
\text { PMN intersticial }\end{array}$ \\
\hline $3^{*}$ & A 46/95 & 3 meses & Ignorada & $\begin{array}{l}\text { tosse, dispnéia, } \\
\text { febre, cianose }\end{array}$ & ignorada & ignorado & $\begin{array}{c}\text { ABT, SMZ/ } \\
\text { TMP, ANF.B, } \\
\text { Amantadina, VM }\end{array}$ & $\begin{array}{l}\text { PNM pelo CMV e } \\
\text { PNEUMONIA } \\
\text { PELOP. CARINII }\end{array}$ \\
\hline 4 & F $91-16$ & 3 meses & vertical & $\begin{array}{l}\text { dispnéia, } \\
\text { cianose }\end{array}$ & hipóxia & condensação & $V M$ & $\begin{array}{l}\text { PNM pelo CMV e } \\
\text { PELO P. CARINNI }\end{array}$ \\
\hline 5 & F $93-95$ & 5 meses & vertical & tosse, dispnéia, & hipóxia & infiltrado & ABT, ANF.B, & PNM pelo CMV \\
\hline 6 & F 95-147 & 2 anos & vertical & $\begin{array}{c}\text { tosse, cianose } \\
\text { dispnéia, febre } \\
\text { DPC }\end{array}$ & hipóxia & $\begin{array}{l}\text { condensação e } \\
\text { infiltrado }\end{array}$ & $\begin{array}{l}\text { ABT, SMZ/ } \\
\text { TMP, RIP }\end{array}$ & $\begin{array}{l}\text { PNM pelo CMV e } \\
\text { PNM e bacteriana }\end{array}$ \\
\hline 7 & $F 96-160$ & 9 meses & vertical & $\begin{array}{l}\text { tosse, febre } \\
\text { DPC }\end{array}$ & hipóxia & $\begin{array}{l}\text { infiltrado e } \\
\text { atelectasia }\end{array}$ & $\begin{array}{c}\text { ABT, SMZ/ } \\
\text { TMP, Ganciclovir }\end{array}$ & PNM bacteriana \\
\hline 8 & F $91-04$ & 5 meses & vertical & $\begin{array}{l}\text { tosse, disonéia, } \\
\text { febre, DPC }\end{array}$ & ignorado & ignorado & ABT, ANF.B & $\begin{array}{l}\text { PNM pelo CMV e } \\
\text { por Gram negativo }\end{array}$ \\
\hline 9 & $F 95-215$ & 3 meses & vertical & $\begin{array}{l}\text { tosse, dispnéia, } \\
\text { febre }\end{array}$ & normal & infiltrado & $\begin{array}{l}\text { ABT,SMZ/ } \\
\text { TMP,VM }\end{array}$ & $\begin{array}{l}\text { PNM pelo CMV e } \\
\text { por Gram negativo }\end{array}$ \\
\hline 10 & F 95-175 & 9 anos & vertical & $\begin{array}{l}\text { tosse, febre, } \\
\text { DPC }\end{array}$ & ignorada & ignorado & $A B T$ & $\begin{array}{l}\text { PMN pelo T. gondii e } \\
\text { PNEUMONIA } \\
\text { INTERSTICIAL } \\
\text { LINFOCÍTICA }\end{array}$ \\
\hline II & F $96-09$ & 6 anos & vertical & tosse, febre & normal & ignorado & $\begin{array}{l}\text { ABT, SMZ/ } \\
\text { TMP, RIP }\end{array}$ & $\begin{array}{l}\text { PMN pelo H. } \\
\text { copsulatum }\end{array}$ \\
\hline 12 & F 90-247 & 7 anos & vertical & $\begin{array}{l}\text { tosse, dispnéia, } \\
\text { febre, cianose, } \\
\text { DPC }\end{array}$ & ignorada & $\begin{array}{c}\text { condensação e } \\
\text { alargamento } \\
\text { mediastinal }\end{array}$ & ABT, RIP & $\begin{array}{l}\text { PMN pelo CMV e } \\
\text { PNM bacteriana }\end{array}$ \\
\hline 13 & F 94-178 & $\begin{array}{l}\text { I ano } \\
7 \mathrm{~m}\end{array}$ & ignorada & $\begin{array}{l}\text { dispnéia, } \\
\text { febre, DPC }\end{array}$ & hipóxia & condensação & ABT, Ganciclovir & $\begin{array}{c}\text { PMN por Gram } \\
\text { negativo }\end{array}$ \\
\hline 14 & F96-11 & 3 meses & vertical & $\begin{array}{l}\text { dispnéia, } \\
\text { clanose }\end{array}$ & hipóxia & infiltrado & $\begin{array}{c}\text { ABT, SMZ/ } \\
\text { TMP, ANF.B, } \\
\text { Ganciclovir, VM }\end{array}$ & $\begin{array}{l}\text { PNM pelo CMV e } \\
\text { PNEUMONIA } \\
\text { PELO P. CARINII }\end{array}$ \\
\hline
\end{tabular}

\section{* Casos do IPPMG}

** SIGLAS: DPC - desnutrição proteico-calórica SMZ/TMP - sulfametoxazol - trimetoprim ABT - antibioticoterapia ANF.B - anfotericina B PMN - pneumonia CMV - citomegalovirus VM - ventilação mecânica

PPC - pneumonia pelo P. carinii PIL - pneumonia intersticial linfocítica 
predominando febre, dispnéia e tosse (Marchevsky et al., 1985).

Em crianças HIV positivas, tem sido observado que a pneumonia pelo $P$. carinii é a infecção pulmonar oportunística mais freqüente (Cunningham, Crain \& Bernstein, 1991). Esses pacientes também são suscetíveis a infecções bacterianas, cujos microorganismos encontrados são os habituais, como o pneumococo e o Haemo phylus influenzae (Rubinstein, Morecki \& Goldman, 1988). Outra doença geralmente observada nos pulmões de crianças, e raramente em adultos infectados pelo HIV, é a Pneumonia Intersticial Linfocítica (Cunningham, Crain \& Bernstein, 1991; Pitt, |99|).

A faixa etária mais acometida pela Pneumonia Intersticial Linfocítica é de crianças acima de dois anos de idade. É comum o achado de baqueteamento digital, aumento de parótidas, linfadenomegalia, hepatoesplenomegalia e alterações radiográficas crônicas do tipo infiltrado difuso, com hipóxia e hipergamaglobulinemia (Parks, 1996; Hauger, 1991; Pitt, 1991). Foi encontrado somente um caso de Pneumonia Intersticial Linfocítica em nossa amostra. Este fato poderia ser explicado pelo predomínio da faixa etária menor que dois anos em nossa população, época em que a Pneumonia Intersticial Linfocítica incide pouco. O nosso único caso correspondeu a criança de nove anos de idade, que apresentava, ao exame físico da internação, baqueteamento digital, linfadenomegalia e hepatoesplenomegalia, não tendo sido descritos aumento de parótida, nem realização de gasometria, de dosagem sérica de lgG ou de radiografia de tórax. À histopatologia, encontrou-se associação à pneumonia por $T$. gondii.

A idade de maior acometimento da pneumonia pelo $P$. carinii é entre três e seis meses de idade e é comum a hipoxemia e a elevação dos níveis séricos de LDH (Hauger, 1991). Em nosso estudo, foram identi- ficados três casos de pneumonia pelo $P$. carinii à histopatologia, em crianças menores de seis meses. A dosagem sérica de LDH foi relatada em um desses casos, com valores dentro da normalidade. Nesse mesmo paciente, foi identificado $P$. carinii em secreção de aspirado traqueal. Nos três casos também foi identificado CMV à histopatologia.

Embora existam relatos de pneumonia pelo P. carinii e Pneumonia Intersticial Linfocítica ocorrendo simultaneamente, na maioria dos casos a Pneumonia Intersticial Linfocítica oferece alguma proteção contra pneumonia pelo $P$. carinii, sendo rara a sua concomitância como causa de pneumonia em crianças com Aids (Cunningham, Crain \& Bernstein, 1991; Pitt, 1991). Prosper et al. (1995), observaram linfopenia CD4 grave associada à resolução completa dos achados radiográficos de Pneumonia Intersticial Linfocítica em cinco de 12 crianças infectadas pelo HIV. A resolução da Pneumonia Intersticial Linfocítica poderia ser a primeira indicação de supressão imune grave, um alerta quanto ao risco aumentado para infecções oportunísticas e um mau sinal prognóstico para crianças infectadas pelo HIV.

No caso de pneumonia bacteriana, o seu diagnóstico presuntivo baseia-se na presença de sinais e sintomas respiratórios de início agudo, radiografia de tórax com infiltrados lobares e hemograma com leucocitose (Hauger, 1991). Em nossa amostra, os oito casos de broncopneumonia à necrópsia estavam associados a outros agentes etiológicos não bacterianos, dificultando a correlação entre os achados clínicolaboratoriais e o etiológico.

Em nossa revisão bibliográfica não encontramos relato de faixa etária de maior acometimento de pneumonia pelo CMV. Pacientes com essa doença apresentam hipoxemia, radiografia simples de tórax com padrão intersticial difuso e, ocasional- mente, infiltrados lobares. Os casos de infecção pulmonar pelo CMV geralmente estão associados a pneumonia pelo $P$. carinii, e a sua confirmação diagnóstica só pode ser feita por estudo histopatólogico de tecido pulmonar (Cunningham, Crain \& Bernstein, |99|). Exames sorológicos usados para diagnosticar citomegalovirose podem ser pouco úteis, já que a presença de anticorpos específicos para o CMV indica infecção, e, não necessariamente doença (Chadwick, 1997). As hemoculturas são mais sensiveis e específicas (Kitchen et al., 1997). Tem sido relatado também elevação de níveis séricos de LDH em pacientes com pneumonia pelo CMV (Waxman et al., 1997).

O CMV é freqüentemente encontrado em secreções respiratórias de crianças com Aids, em associação ao P. carinii. Mesmo sem terapia específica para o CMV nesses casos, os pacientes evoluem sem agravamento do seu quadro clínico. Além disso, esse vírus é isolado de secreções pulmonares obtidas durante broncoscopia de crianças HIV positivas, com contagens baixas de CD4, sem sintomas respiratórios (Kitchen et al., 1997). Trabalhos têm evidenciado doença citomegálica em pulmões, geralmente sem sintomas gerais sugestivos de doença pelo CMV (Chadwick, 1997). Por isso, questiona-se a ação patogênica do CMV em pacientes com Aids e comprometimento pulmonar.

Em nossa amostra, nove pacientes apresentavam achados histopatológicos de pneumonia pelo CMV, porém em apenas um deles o CMV foi encontrado isoladamente. Este era um lactente de cinco meses de idade, cuja evolução da doença respiratória foi aguda com tosse, febre e dispnéia. O hemograma apresentava anemia e leucopenia, as sorologias foram negativas, à gasometria observou-se hipóxia e à radiografia simples de tórax, infiltrado bilateral. Na maioria dos casos de diagnóstico histo- 
patológico de pneumonia pelo CMV, não foi observada correlação com os resultados da sorologia, exceto no caso 5, em que a IgM para CMV foi positiva. Em um caso, no qual observou-se também broncopneumonia, a LDH se encontrava elevada.

Em crianças infectadas pelo HIV há poucos dados disponíveis sobre a infecção pelo M. tuberculosis (Lambert, Nogueira \& Abreu, 1996). Enquanto altas taxas de infecção pelo HIV são relatadas em crianças com tuberculose em alguns países, estudos clínicos e de necrópsias de crianças HIV positivas têm mostrado que a co-associação com tuberculose não é comum (De Cock et al., 1996). No presente estudo não houve casos desta associação.

Estudos de necrópsias mais recentes têm sido diferentes daqueles da década passada. Infecções fúngicas, virais, bacterianas e por micobactérias têm sido mais comuns do que pneumonia pelo $P$. carinii e Pneumonia Intersticial Linfocítica, provavelmente devido à maior difusão da profilaxia para pneumonia pelo $P$. carinii, assim como da sua terapia empírica precoce, na maioria dos pacientes infectados pelo HIV com acometimento pulmonar. Em relação à Pneumonia Intersticial Linfocítica, o tratamento precoce da criança HIV positiva com antiretrovirais pode estar sendo o responsável pela queda em sua ocorrência entre os pacientes infectados pelo HIV (Drut, 1997; Johann-Liang, Cervia \& Noel, 1997; Masini et al., 1994; Moran et al., 1994; Reik, Rodriguez \& Hensley, 1995; Joshi et al., 1986; Marchevsky et al., 1985 ). No presente trabalho, por falta do diagnóstico da infecção pelo HIV antes da internação estudada, poucos foram os casos que receberam profilaxia para pneumonia pelo $P$. carinii e/ ou drogas antiretrovirais Desses trabalhos anatomoclínicos, o mais recente e com população de países latino-americanos, como a nossa, foi o de Drut et al. (1997) que analisaram laudos de necrópsias completas, cujo órgão mais acometido foi o pulmão, encontrando, com maior freqüência, Candida sp. e P. carinii. seguidos pelas infecções virais, com predomínio do CMV. Joshi et al. (1986) obtiveram resultados semelhantes aos nossos, sendo o CMV e as bactérias, os agentes mais identificados ao exame anatomopatológico do pulmão de crianças com Aids. Em outros estudos as bactérias foram os agentes etiológicos mais comuns das pneumonias, ocorrendo em aproximadamente $50 \%$ dos casos (Moran et al., 1994 e Reik, Rodriguez e Hensley, 1995).

Vários microorganismos têm sido isolados a partir de fragmentos de pulmão de crianças com Aids, limitando qualquer tentativa de correlacionar a apresentação clínica com um agente etiológico específico. A pneumonia pelo $P$. carinii, principalmente, tem sido descrita associada a outros patógenos, principalmente ao CMV (Chadwick, 1997). Glatman-Freedman et al. (1998), relataram três casos incomuns de crianças com Aids infectadas simultaneamente com P. carinii e Streptococcus pneumonice. A coexistência de outros patógenos com pneumonia pelo $P$. carinii é tão comum que Miller \& Walker (1996) sugerem que, mesmo nos casos em que a pneumonia pelo $P$. carinii é o único diagnóstico estabelecido por métodos não invasivos, a investigação diagnóstica não deve ser considerada completa caso não haja resposta clínica à terapia específica. Até $25 \%$ dos pacientes, com suspeita clínica de pneumonia pelo $P$. carinii apresentam um outro diagnóstico e aproximadamente $18 \%$ dos pacientes com AIDS e pneumonia pelo $P$. carinii comprovada à broncoscopia, têm uma segunda infecção coexistente tratável. Em nosso estudo foi freqüente a associação de microorganismos à histopatologia pulmonar, sendo a associação do CMV e bactérias, a mais encontrada. A pneumonia pelo $P$. carinii foi detectada em três pacientes e em todos eles estava associada ao CMV. O isolamento de mais de um organismo não possibilitou a identificação de um determinado patógeno como responsável pelo quadro clínico apresentado pelo paciente. No entanto, a freqüência com que achados histopatológicos de doença pulmonar pelo CMV foram observados, deve levantar a suspeita dessa etiologia nos quadros de pneumonia em crianças com Aids acompanhadas nos serviços envolvidos.

À semelhança de Moran et al. (1994), no presente estudo, em todos os casos, havia uma causa passível de tratamento não reconhecida durante a internação, apontando para a valorização de estudos histológicos em pacientes HIV positivos, nos quais a alta freqüência de acometimento pulmonar, assim como a dificuldade em identificar o agente etiológico das pneumonias limitam o seu tratamento. Dessa forma, pelo achado freqüente de CMV em nosso estudo, e pela administração pouco difundida de terapia específica para tal patógeno na população com doença pulmonar e Aids, ficaria a sugestão de se valorizar a pneumonia por esse vírus em nosso meio, e as conseqüentes providências terapêuticas oportunas.

\section{Conclusões}

I) O perfil das crianças com Aids analisadas neste estudo foi caracterizado predominantemente por:

- faixa etária menor que cinco anos, transmissão vertical do HIV, quadro clínico constituído de tosse, febre e dispnéia e exame físico de internação com desnutrição protéico-energética, linfonodomegalia e hepatoesplenomegalia;

- anemia e hipóxia;

- padrões radiológicos tipo infiltrado e condensação;

- alterações pulmonares sugestivas de pneumonia viral ao exame anatomopatológico; 
2) $\mathrm{O} C M V$, e a seguir bactérias, foram os agentes etiológicos mais freqüentes das doenças pulmonares;

3) A ocorrência de múltiplos patógenos foi um achado relevante ao exame histopatológico de fragmentos pulmonares, ressaltando-se a associação do CMV com bactérias;

4) Pneumonia Intersticial Linfocítica e pneumonia pelo $P$. carinii não foram causas comuns de doenças pulmonares, contrastando com os dados da literatura.

\section{SUMMARY}

\section{NeCroscopic Study OF I 4 CHILDREN WITH AIDS AND PNeUMONIA}

BACKGROUND. To describe clinical, labo ratorial, radiological, and histopathological lung findings from necroscopy of aidetic children with pulmonary disease.

Material And Methods. Fourteen children admitted at the Hospital Universitário Antônio Pedro - Universidade Federal Fluminense, Niterói, RJ, and Instituto de Puericultura e Pediatria Martagão Gesteira Universidade Federal do Rio de Janeiro, Rio de Janeiro, RJ, between 1989 and 1996, were revised in a retrospective survey.

REsULTS. Eight were males (57\%). The median age was 1.2 years old (from three months to nine years). Nine children (64.4\%) were younger than 24 months old. The HIV transmission was vertical in 10 (71\%) children. In these cases, five mothers were contaminated from heterosexual relations. Pneumonia $(n=8)$, oral candidiasis $(n=8)$, and diarrhea $(n=5)$ were the most common previous conditions. The most frequent signs and symptoms on admission were fever $(n=12)$, respiratory distress $(n=10)$, cough $(n=10)$, peripheral lymphadenopathy $(n=11)$, hepatomegaly and/or splenomegaly $(n=10)$, and malnutrition $(n=9)$. The chest $x$-rays findings were condensation $(n=5)$ and diffuse infiltrates $(n=6)$ patterns. The microscopic lung characteristics were compatibles with pneumonia by cytomegalovirus (CMV) $(n=9)$, bacteria $(n=8)$, Pneumo cystis carinii $(n=3)$, Toxoplasma gondii $(n=1)$, Hystoplasma capsulatum $(n=1)$ and Lymphocytic interstitial pneumonia $(n=1)$. The association between CMV and bacteria was observed in six cases.

Conclusions. Age less than two years old, vertical transmission, inespecific clinical presentation of pneumonia, and infiltrates and condensation patterns at the $x$-rays were the predominant characteristics. Cytomegalovirus and bacteria were the most common etiologic agents, being their association frequent. Lymphocytic interstitial pneumonia and pneumonia by P. carinii were not common causes of pulmonary disease. [Rev Ass Med Brasil 2001; 47(2): 129-36]

Key Words: Autopsy. Lung. Children. Aids. Necroscopy.

\section{Agradecimentos}

Ao Departamento de Doenças Infecciosas do Instituto de Puericultura e Pediatria Martagão Gesteira da Universidade Federal do Rio de Janeiro, em especial à Dra Thalita Fernandes de Abreu e ao Dr. Adauto Dutra Moraes Barbosa, professor da Universidade Federal Fluminense.

\section{REFERÊNCIAS}

I. Hauger SH. Approach to the pediatric patient with HIV infection and pulmonary symptoms. J Pediatr 1991; 119: 25-33.

2. Bye MR, Cairns-Bazarian AM, Ewig JF. Markedly reduced mortality associated with corticosteroid therapy of Pneumocystis carinii pneumonia in children with acquired immunodeficiency syndrome. Arch Pediatr Adolesc Med 1994; |48: 638-4I.

3. Lambert JS, Nogueira SA, Abreu TF (Edit.). Manual para o acompanhamento da criança infectada pelo HIV. Rio de Janeiro: Fogarty Foundation, UFRJ, Instituto de Puericultura e Pediatria Martagão Gesteira, 1996.

4. Moran CA, Suster S, Pavlova Z, Mullick FG, Koss MN. The spectrum of pathological chan- ges in the lung in children with acquired immunodeficiency syndrome: an autopsy study of 36 cases. Hum Pathol 1994; 2: 877-82,.

5. Johann-Liang R, Cervia JS, Noel GJ. Characteristics of human immunodeficiency virusinfected children at the time of death: an experience in the 1990s. Pediatr Infect Dis J 1997; 16: | |45-50,.

6. Centers for Disease of Control. AIDS among children - United States, 1996. Morb. Mortal. Wkly Rep. [online]. v. 45, n. 46, p. 1005-1010, 1996. [06/07/97]. Disponível na Internet. <http:/ /www.medscape.com/govmt/CDC/MMWR/ | 996/nov/4546/4546. |/4546. I.html>

7. Boletim DST/AIDS. [online]. Brasília: Ministério da Saúde, Programa Nacional de DST/ AIDS, n. 3, 1998. [19/12/98]. Disponível na Internet: <http://www.aids.gov.br>

8. Courpotin C. HIV infection in children: what's new in 1996. Place of pulmonary complications. Pediatr Pulmonol 1997; 16: 190-191.

9. Reik RA, Rodriguez MM, Hensley, GT. Infections in children with Human Immunodeficiency Virus/Acquired Immnodefficiency Syndrome: an autopsy study of 30 cases in South Florida, 1990-1993. Pediatr Pathol Lab Med 1995; 15: 269-281.

10. Joshi W, Oleske JM, Saad Setal. Pathology of opportunistic infections in children with acquired immunodeficiency syndrome. Pediatr $\mathrm{Pa}$ thol 1986; 6: |45-50,

I I. Parks W. Human immunodeficiency virus. In: Nelson, W. E., eds. Nelson textbook of Pediatrics, 15th ed. Philadelphia, PEN. W. B. Saunders, 1996; 916-919.

12. Miller KD, Walker RE. A practical approach for diagnosing AIDS- associated pulmonary disease. The AIDS Reader. [online]. v. 6, n. 2, p. 5865, 7I, 1996. [06/07/97]. Disponível na Internet: <http://HIV.medscape.com/SCP/TAR/ | 996/v06.n02/a391.miller/a39.miller.html>

13. Marchevsky A, Rosen MJ, Chrystal G, Kleinerman J. Pulmonary complications of the acquired immunodeficiency syndrome: a clinicopathologic study of 70 cases. Hum Pathol 1985; 16: 659-670.

14. Cunningham SJ, Crain EF, Bernstein LJ. Evaluating the HIV-infected child with pulmonary signs and symptoms. Pediatr Em Care 1991;7: 32-37.

15. Rubinstein A, Morecki R, Goldman H. Pulmonary disease in infants and children. Clin Chest Med 1988; 9: 507-17.

16. Pitt, J. Lymphocytic intersticial pneumonia. Pediatr Clin North Am I 991; 38: 89-95.

17. Kitchen BJ, Engler HD, Gill VJ et al. Cytomegalovirus infection in children with human immunodeficiency virus infection. Pediatr. Infect Dis J 1997; 16: 358-363.

18. Chadwick EG. Cytomegalovirus pneumonitis in children with AIDS. Pediatr Pulmonol 1997; 16: 197-198.

19. Prosper M, Omene JA, Ledlie S, Odita JC. Clinical significance of resolution of chest $X$-ray 
findings in HIV-infected children with lymphocytic intersticial pneumonitis (LIP). Pediatr Radiol 1995; 25: 243-246.

20. Waxman AB, Goldie SJ, Brett-Smith H, Matthay RA. Cytomegalovirus as a primary pulmonary pathogen in AIDS. Chest 1997; I I: | 28- 134 .

21. De Cock KM, Binkin NJ, Zuber PLF, Tappero
JW, Castro KG. Research issues involving HIV associated tuberculosis in resource-poor countries. JAMA 1996; 276: I 502-1507.

22. Drut R, Anderson V, Greco MA, Gutiérrez C, Leon-Bojorge B et al. Opportunistic infections in pediatric HIV infection: a study of 74 autopsy cases from Latin America. Pediatr Pathol Lab Med 1997; 17: 569-576.
23. Masini T, Chinaglia D, Ghidoni P, Gullota F. Autoptic findings in HIV-I positive children. Klin Pädiatr 1994; 206: 45-49.

24. Glatman-Freedman A, Ewig JM, Dobroszicki J, Mitsudo S, Glaser JH. Simultaneous Pneumocystis carinii and pneumococal pneumonia in human immunodeficiency virus-infected children. J Pediatr 1998; |32: |69-171.

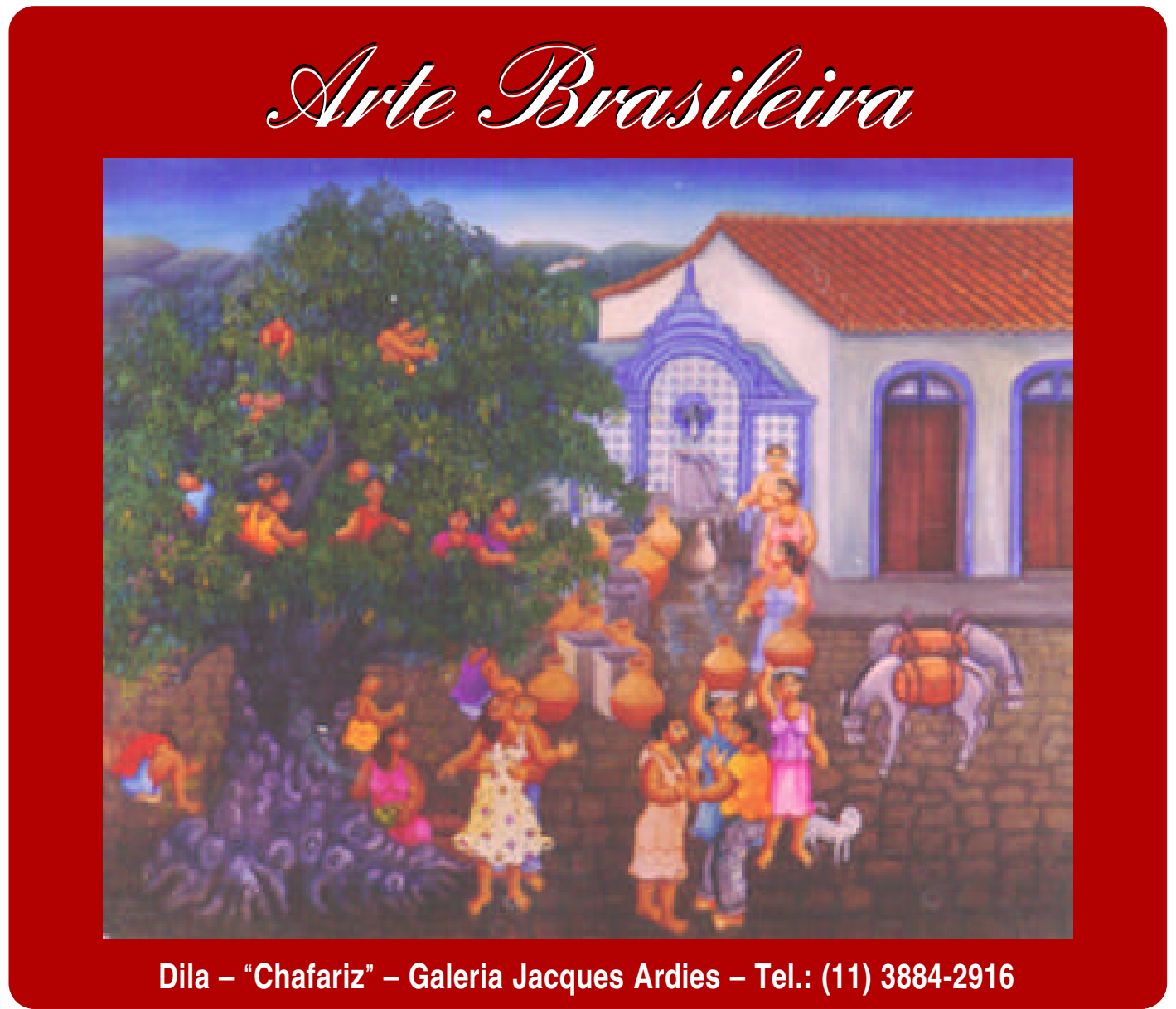

